\title{
Traditional Uses of Medicinal Plants in Polonnaruwa District in North Central Province of Sri Lanka
}

\author{
Mayuri Tharanga Napagoda ${ }^{D},{ }^{1}$ Thamudi Sundarapperuma, ${ }^{2}$ Diroshi Fonseka, ${ }^{2}$ \\ Sachinthi Amarasiri, ${ }^{2}$ and Prabath Gunaratna ${ }^{2}$ \\ ${ }^{1}$ Department of Biochemistry, Faculty of Medicine, University of Ruhuna, Galle 80000, Sri Lanka \\ ${ }^{2}$ Faculty of Allied Health Sciences, University of Ruhuna, Galle 80000, Sri Lanka \\ Correspondence should be addressed to Mayuri Tharanga Napagoda; mayurinapagoda@yahoo.com
}

Received 5 January 2019; Revised 9 April 2019; Accepted 15 May 2019; Published 28 May 2019

Academic Editor: Marie-Aleth Lacaille-Dubois

Copyright (c) 2019 Mayuri Tharanga Napagoda et al. This is an open access article distributed under the Creative Commons Attribution License, which permits unrestricted use, distribution, and reproduction in any medium, provided the original work is properly cited.

\begin{abstract}
Sri Lanka harbors over 3000 plant species, and most of these plants have been of immense importance in the traditional systems of medicine in the country. Although there is a rich reserve of indigenous knowledge on medicinal plants, in-depth studies have not been pursued yet to compile the ethnoflora with traditional medicinal applications for the scientific community. Thus, as a continuation of our ethnobotanical inventory work in different regions in the country, the present study was carried out in one of the administrative districts in the North Central area of Sri Lanka known as Polonnaruwa district. The information on the significance of medicinal plants as curative and preventive agents of diseases was collected through semistructured and openended interviews from 284 volunteers who were randomly recruited for the study. Ethnobotanical data were analyzed using relative frequency of citation (RFC), family importance value (FIV), and use value (UV). Out of the total participants, 53.7\% claimed the use of herbal remedies. A total of 64 medicinal plants belonging to 42 plant families were recorded, out of which Coriandrum sativum L. (RFC $=0.163$ ) was the most cited species. Out of the 42 plant families recorded, the FIV was highest in Zingiberaceae. Coscinium fenestratum (Goetgh.) Colebr. was found as the plant with the highest use value. Furthermore, the majority of the nonusers of the herbal remedies were willing to adopt herbal products upon the scientific validation of their therapeutic potential. This study revealed that the indigenous herbal remedies are still popular among the local communities in the study area.
\end{abstract}

\section{Introduction}

Medicinal plants have been used since time immemorial in both developing and developed countries; for example, plants were considered as the material basis of traditional Chinese medicine (TCM) as well as many other ethnic medicine traditions in China [1], while the utilization of medicinal plants as a fundamental component of the African traditional health-care system is believed as the oldest and the most assorted of all therapeutic systems [2]. Similarly, the Indian subcontinent is considered as a vast repository of medicinal plants that have been used in indigenous medical treatments, and even in the present era of modern medicine, traditional health-care systems based on plants and plant- derived products are therapeutically employed on the Indian subcontinent [3]. In the Sri Lankan context, indigenous systems of medicine are widely popular among large segments of the Sri Lankan population despite the influx of modern Western medicine. In general, the traditional systems of medicine available in the country are of four types, namely, Ayurveda, Siddha, Unani, and Deshiya Chikitsa. Plants and plant-based formulations are considered as essential components of the Ayurveda and Deshiya Chikitsa systems [4]. Among the native flora of Sri Lanka, more than 1400 plants are employed for medicinal purposes [5]. Considering the ethnobotanical data in other developing countries in the world, particularly in the neighboring country (India) [6], we could speculate that herbal 
preparations are more popular among the rural communities in Sri Lanka as well. Hence, a rich reserve of indigenous knowledge of herbal remedies for various ailments is expected to have accumulated especially in the rural areas of the country. The documentation of Sri Lankan medicinal plants to the scientific community was initiated during the colonial period of the country, specially with the descriptions of plant specimens collected by Paul Hermann in the 1670s and also with Icones Plantarum Malabaricarum (1694-1718) [7, 8]. Although these sources represent a rich source of ethnobotanical knowledge from colonial Ceylon, only a handful of ethnobotanical studies have been conducted over the recent years to document the traditional knowledge on medicinal values of plant species used in indigenous medicine $[9,10]$. In addition, the book series written by Jayaweera in 1982 on "Medicinal plants (indigenous and exotic) used in Ceylon" [11] are still popular among scientists who are working on medicinal plants and their bioactivities; however, the scientific validation of these traditional claims is still at its infancy. Thus, as a continuation of our ethnobotanical inventory work in different administrative areas in Sri Lanka, the present study was undertaken to assess the significance and contribution of medicinal plants/herbal therapeutics to the day-to-day life of the inhabitants of Polonnaruwa district in the North Central region in Sri Lanka.

As evident from the ethnobotanical studies conducted in other South Asian countries as well as in Africa, the rural communities exploit plants that are easily available in their surroundings for food and medicaments [12-14]. For example, a recent study conducted in Northern Pakistan revealed that the local communities have a rich accessibility of medicinal plants; thus, they opt herbal remedies as lowcost health care for respiratory disorders [15]. Moreover, in the case of herbal therapeutics, people are generally aware about the harmful effects of synthetic medicines, thus realize the importance of a more natural way of life [10]. Moreover, the factors like low financial conditions and unavailability of modern health-care facilities would also limit the access of rural people to synthetic medicines [16]. Hence, the study area for this research has a high potential for utilization and consumption of medicinal plants due to the wide availability of valuable medicinal plants that are unique to the dry zone of Sri Lanka, as well as the presence of rural agricultural communities. Considering all these factors, we hypothesized that the inhabitants in the study area for this research widely utilize medicinal plants as easy and reliable remedies for common disease conditions.

\section{Materials and Methods}

2.1. Study Area. Polonnaruwa district is located in the North Central Province of Sri Lanka (Figure 1, Supplementary 1) and has an area of $3,293 \mathrm{~km}^{2}$. The district is divided into seven divisional secretariat divisions, which are further subdivided into 295 "Grama Niladhari" divisions. There are 637 villages, and the total population of the district is reported as 403,335 . The majority of the people in the district are engaged in agriculture and animal husbandry. The forest

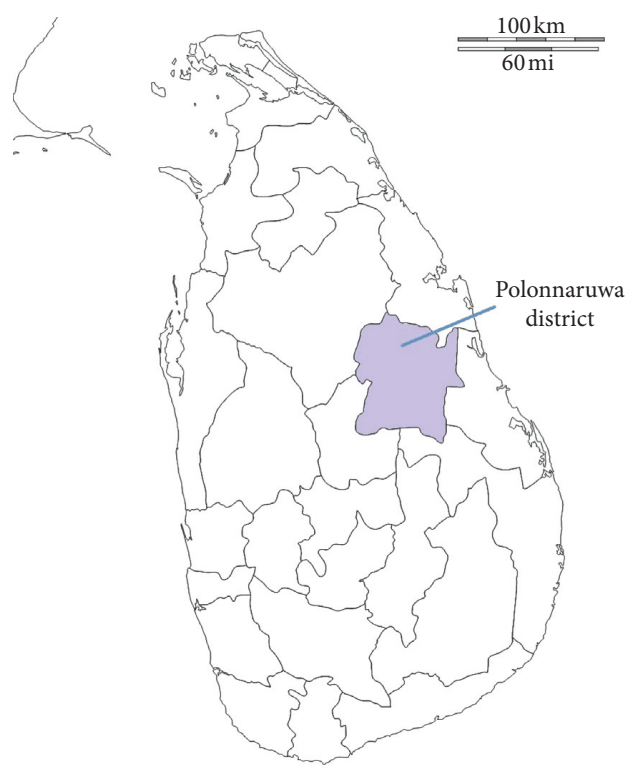

Figure 1: Location of Polonnaruwa district.

coverage, including the grasslands and marshy lands, is estimated as 346,638.2 ha [17]. Twelve government hospitals located within the district provide modern health-care facilities, while 16 Ayurvedic hospitals and a large number of traditional healers within the local communities are responsible for the provision of traditional health-care system.

\subsection{Ethnobotanical Field Survey and Data Collection.} Medicinal plant use was documented in all seven divisional secretariat areas (i.e., Dimbulagala, Elahera, Hingurakgoda, Lankapura, Medirigiriya, Thamankaduwa, Welikanda; see Supplementary 1) in Polonnaruwa district. This survey was carried out from August 2015 to March 2018, and the data were collected from 284 volunteers from the general population of the district who were aged above 30 years, following the method described by Napagoda et al. [10]. In brief, the participants were selected randomly from a list of households in each divisional secretariat area, and visits were made to each of those households for data collection. Informed consent was obtained from each participant in writing prior to the study. A questionnaire was used to collect the information on local name of the plants, source, part(s) used, method of traditional preparation, and some demographic information of the informants such as age, gender, and educational background (Supplementary 2).

The ethical approval was obtained from the ethical review committee, Faculty of Medicine, University of Ruhuna, Sri Lanka. SPSS version 20 was used to recode the collected data.

2.3. Plant Specimen Collection and Preservation. Plant species used as herbal remedies were collected, dried, preserved, and mounted on herbarium sheets. The plant materials were identified by one of the authors (MTN), who is a botanist. Botanical names and families were verified using book series titled "Revised Handbook to the Flora of Ceylon" [18] and 
"Medicinal plants (indigenous and exotic) used in Ceylon" [11]. The botanical names have also been checked with the data available at http://www.theplantlist.org. The specimens were deposited at the Herbarium in the Department of Biochemistry, Faculty of Medicine, University of Ruhuna, Sri Lanka.

\subsection{Quantitative Analysis of the Ethnobotanical Information.} The knowledge on the usage of medicinal plants was quantitatively assessed by the relative frequency of citation (RFC), family importance value (FIV) of a plant family, and use value (UV) as described in our previous study [10] and the method of Kayani et al. [15] by substituting in the relevant equations given below. RFC and FIV were calculated to quantitatively determine the consensus between informants on the use of medicinal plants in the region as it gives the local importance of a species or a family $[15,19,20]$.

The value of RFC for a particular species of medicinal plants is based on the citing percentage of informants for that particular species, where $\mathrm{RFC}=\mathrm{FC} / \mathrm{N}(0<\mathrm{RFC}<1)$, in which RFC is the relative frequency of citation, FC is the number of informants who mentioned the species, and $N$ is the total number of informants participating in the study.

Family importance value (FIV) of a plant family was calculated by taking the percentage of informants mentioning the family, where FIV $=\mathrm{FC}$ (family) $/ N \times 100$, in which FC is the number of informants mentioning the plant family and $N$ is the total number of informants participating in the study.

Use value indicates the relative importance of plant species known locally, and the following formula was used to determine $U V: U V_{i}=\sum U_{i} / N_{i}$, in which $U_{i}$ is the number of use reports described by each informant for species $i$ and $N$ is the total number of informants describing the specific species $i$.

\section{Results and Discussion}

As speculated, the results of this study revealed that the majority of the inhabitants who have participated in this study depended on the indigenous plant resources as treatments and preventive measures against a number of disease conditions.

Out of the total of 284 informants, 132 (53.7\%) claimed the use of medicinal plants for the treatment of various ailments such as diabetes, inflammatory conditions, and skin diseases, while the rest of the informants (46.3\%) mentioned the nonadherence to herbal remedies. In addition, these plants are also used as energy boosters and cosmetics. Among those people, $47.6 \%$ firmly believed in the safety and low adverse effects associated with the herbal formulations and mentioned this as a reason for their preference. In addition, the previous success with herbal remedies (35.86\%) was also a main contributing factor for the people to continue with plant-based therapies. Unlike the observations of our previous ethnobotanical study conducted in Gampaha District, Western Province of Sri Lanka [10], some people $(2.76 \%)$ stated that the nonavailability of modern health-care facilities in their villages was a reason for them to opt for herbal remedies. The majority of the users (67.9\%) claimed the use of herbal preparations at the initial stage of a disease before going for any other medications, while $26.01 \%$ have mentioned the simultaneous usage with other medications. Only $6.1 \%$ stated the use of herbal therapeutics as a last resort, when other treatment methods have failed. The knowledge of the herbal remedies had transferred through generations while the influence of media in promoting the use of herbal therapeutics could not be neglected (Table 1).

The study revealed the use of 64 medicinal plants belonging to 42 plant families, out of which Coriandrum sativum $\mathrm{L} . \quad(\mathrm{RFC}=0.163)$ was the most cited species, followed by Zingiber officinale Roscoe $(\mathrm{RFC}=0.146)$ and Hygrophila auriculata (Schumach.) Heine $(\mathrm{RFC}=0.109)$. The family importance value was highest in Zingiberaceae $(22.8 \%)$ (Table 2). The highest use value was reported for Coscinium fenestratum (Goetgh.) Colebr. The most dominant life form of the species reported was herbs $(37.5 \%$; Figure 2). The most frequently used part of the plant was leaves (36.2\%; Figure 3), followed by seeds/fruits (18.9\%). Medicinal plants used in folk herbal remedies were prepared and administered in various forms. The most common preparation method was infusion $(34.4 \%)$ while $14.9 \%$ were used in the form of a paste (Figure 4). The percentage of oral administration $(71.1 \%)$ of herbal preparation was much higher than the external or topical application (24.3\%) and inhalation (4.6\%). Most of the crude drugs were prepared from single plant species; however, combinations of multiple species as well as the use of adjuvants such as honey, sugar, coconut milk, salt, and coconut oil have also been reported. For example, a paste prepared from the fruit of Myristica fragrans Houtt. with the juice of Citrus aurantifolia (Christm.) Swingle is a common remedy for stomachache while honey or sugar is added to most of the infusions to reduce the bitter taste.

The summary of the medicinal plant species used in Polonnaruwa district to treat various disease conditions is given in Table 3.

As depicted in Figure 5, herbal remedies were used by the inhabitants of Polonnaruwa district against 15 broad categories of ailments/conditions reporting the highest number of species against swellings/pains or sprains. Further, the local people in the study area utilize medicinal plants (around 30 plant species) for the treatment of other classical inflammatory symptoms like fever $[10,21]$ or chronic inflammatory diseases like asthma [22].

Interestingly, the medicinal uses of some of the plants mentioned by the informants have not been documented in the literature particularly in the popular book series on Sri Lankan medicinal plants by Jayaweera [11], for example, the use of Spondias dulcis Parkinson for high blood pressure and Hemidesmus indicus (L.) R. Br. ex Schult., Artocarpus heterophyllus Lam, and Scoparia dulcis L. for diabetes. Therefore, the documentation of this rich undocumented ethnobotanical knowledge could offer new avenues for pharmacological investigations on prospective new drugs of herbal origin. Moreover, plant species like Asparagus racemosus Willd, Terminalia bellirica (Gaertn.) Roxb., Piper 
TABLE 1: Statistics on the usage of herbal therapeutics.

\begin{tabular}{lc}
\hline Parameter & Percentage \\
\hline Demographic data of regular users & \\
Gender & \\
Male & 59.8 \\
Female & 40.2 \\
Age group (years) & \\
30-45 & 34.09 \\
$46-60$ & 38.64 \\
61-75 & 24.24 \\
>75 & 3.03 \\
Educational background & \\
University degree/diploma and above & 2.3 \\
12 years of school education & 15.2 \\
1-11 years of school education & 82.5 \\
No schooling & 0 \\
\hline Source of information/knowledge & \\
From parents/grandparents & 60.42 \\
Neighbours/friends & 13.89 \\
Doctors/traditional physicians & 7.64 \\
Media & 13.19 \\
Own experience & 4.86 \\
\hline Reason for usage & \\
Safe/less side effects & 47.59 \\
Previous success & 35.86 \\
Easy access to the plant materials & 13.79 \\
High cost of other treatment methods & 0 \\
Nonavailability of modern health-care facilities & 2.76 \\
\hline
\end{tabular}

TABLE 2: Family importance value (FIV) of the ten plant families with the highest FIV.

\begin{tabular}{lc}
\hline Family & FIV (\%) \\
\hline Zingiberaceae & 22.8 \\
Apiaceae & 19.9 \\
Acanthaceae & 18.3 \\
Rutaceae & 12.6 \\
Fabaceae & 10.2 \\
Amaranthaceae & 9.7 \\
Menispermaceae & 9.3 \\
Apocynaceae & 8.9 \\
Cucurbitaceae & 8.1 \\
Meliaceae & 7.7 \\
\hline
\end{tabular}

betle L., Murraya koenigii (L.) Spreng., Citrus aurantium L., Citrus aurantifolia (Christm.) Swingle, and Zingiber officinale Roscoe have been identified as remedies for snake bites in a recent ethnobotanical study conducted in Western and Sabaragamuwa Provinces in Sri Lanka [9]; however, none of the informants participated in the present study mentioned about the utility of those plants in the treatment of snake bites. Besides, some of the informants mentioned that the wealth of knowledge is rapidly diminishing due to the dearth of elderly people who are knowledgeable on folklore medicine as well as lack of interest in younger generation to systematically study these traditional healing systems. Thus, our findings would enable the preservation of local knowledge which is obtained by trial and error and transferred over generations. In addition, a dramatic degradation

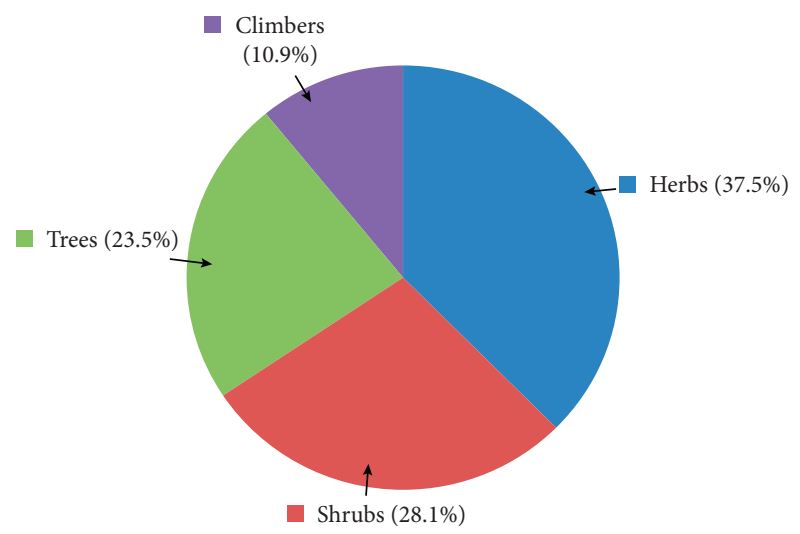

FIgURE 2: Life form of the plants used as herbal remedies.

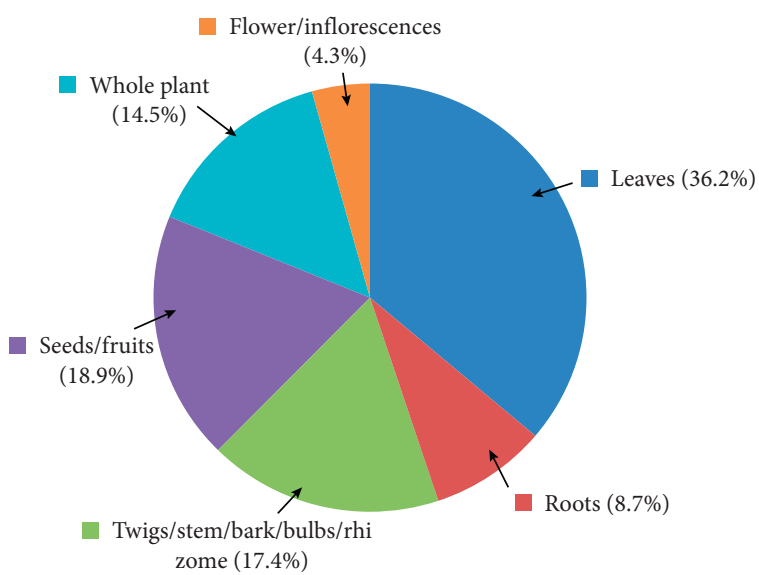

FIgURE 3: Plant parts used in herbal preparations.

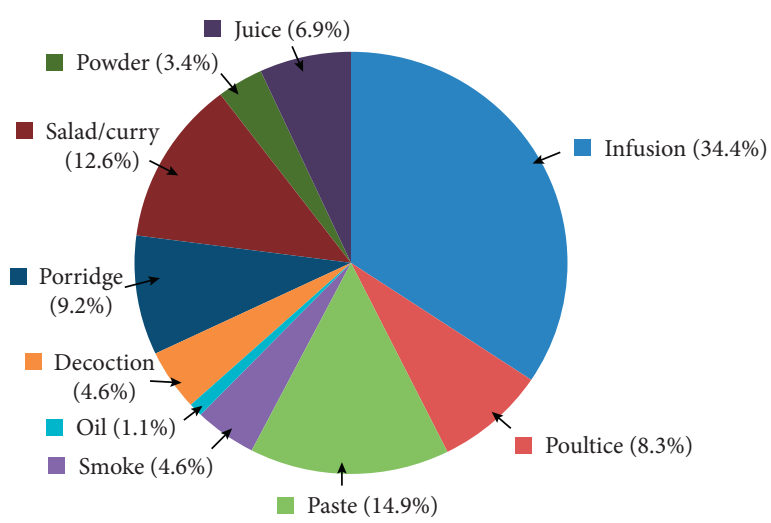

FIgURE 4: Mode of utilization of plants to treat various disease conditions.

of habitat due to construction work and the ruthless use and overexploitation of medicinal plants by local people and the traders of medicinal plants solely for commercial purposes were observed during the field survey. As an example, it has been mentioned that there is a high demand in the local market specially for Salacia reticulata Wight, a plant which was also documented in Icones Plantarum Malabaricarum as 


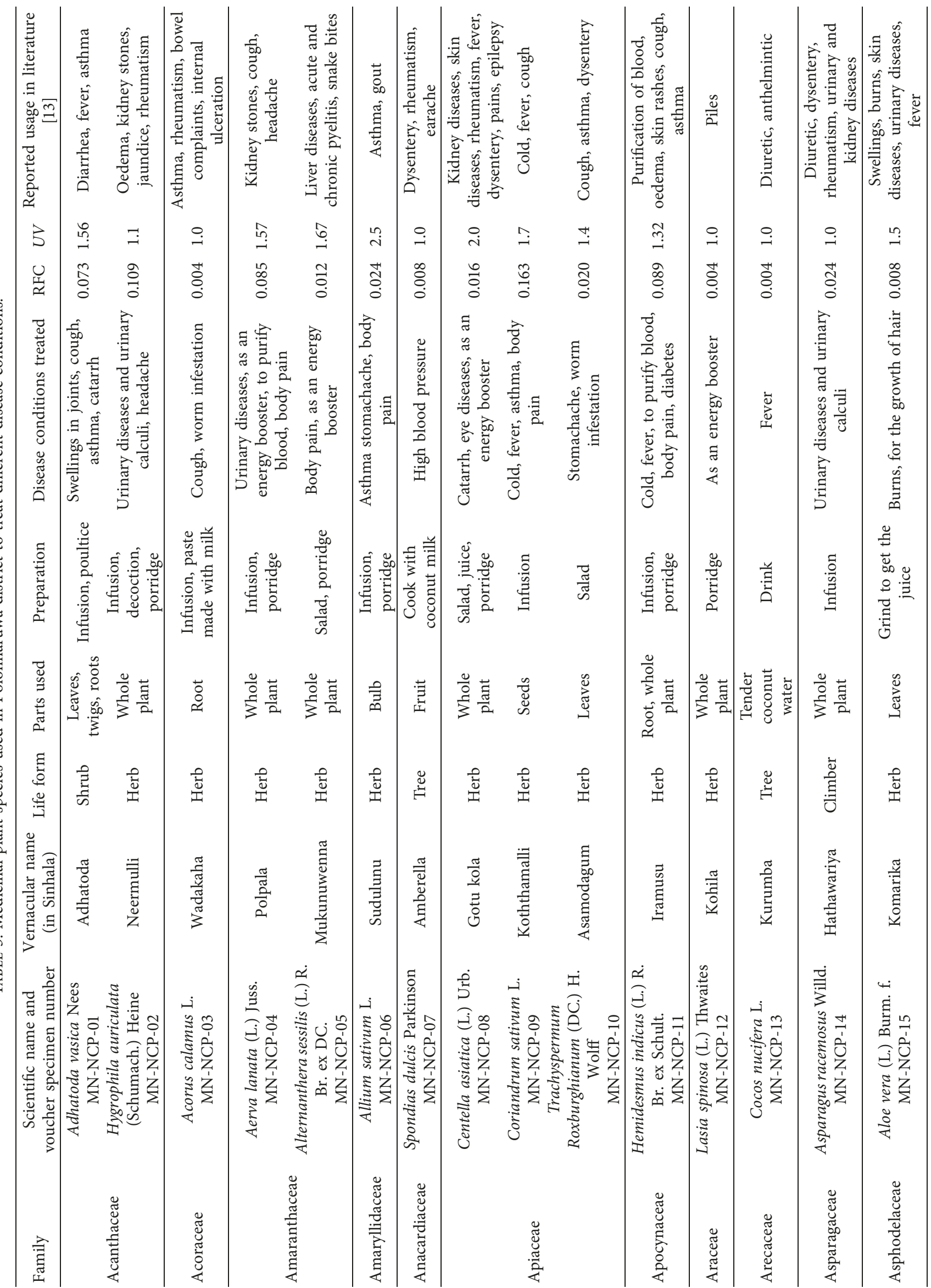




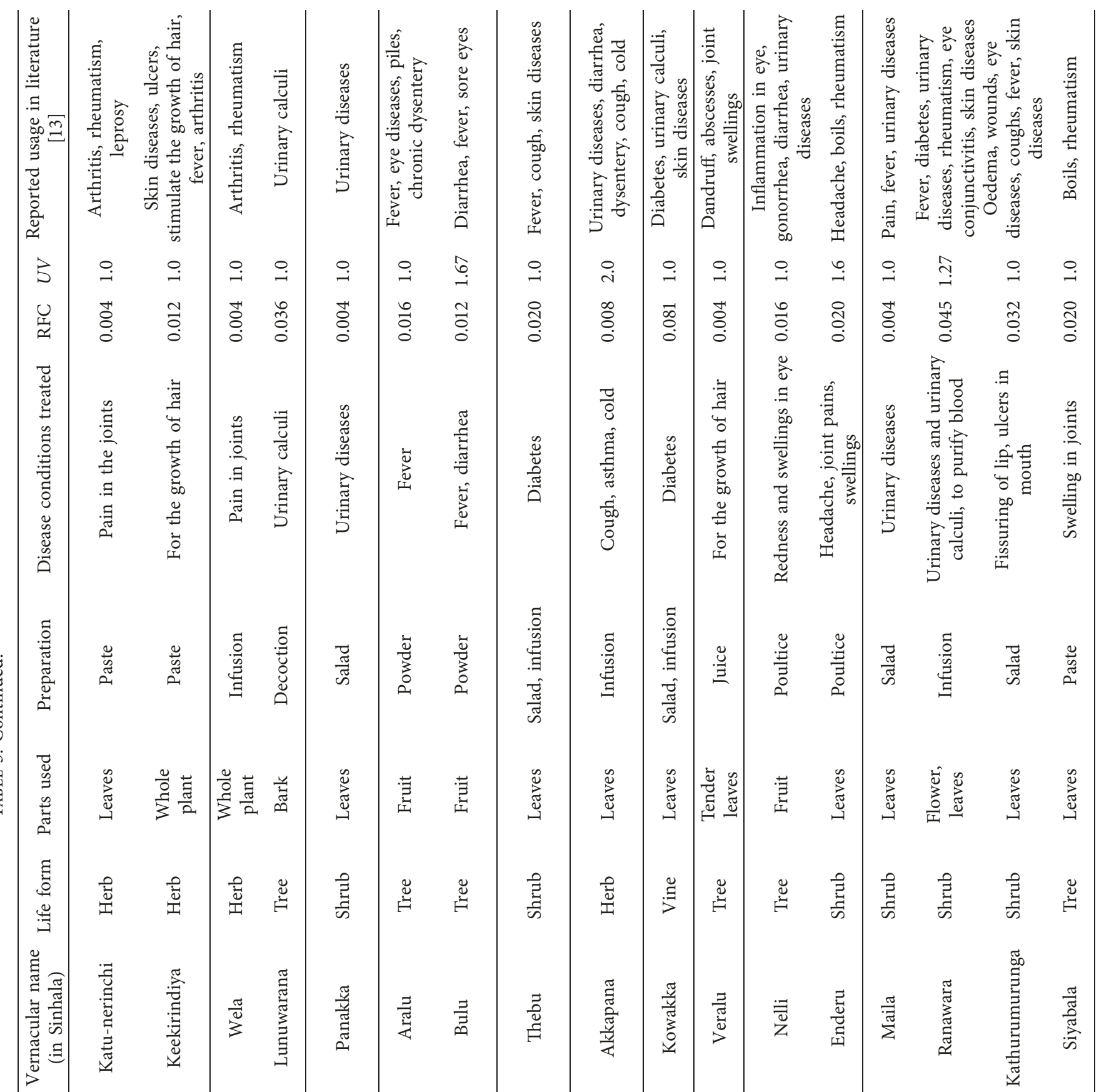

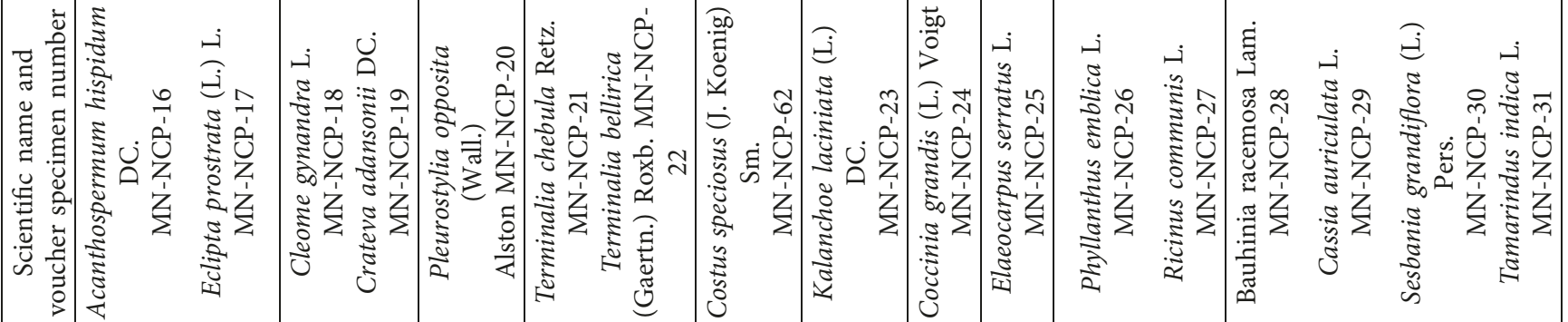

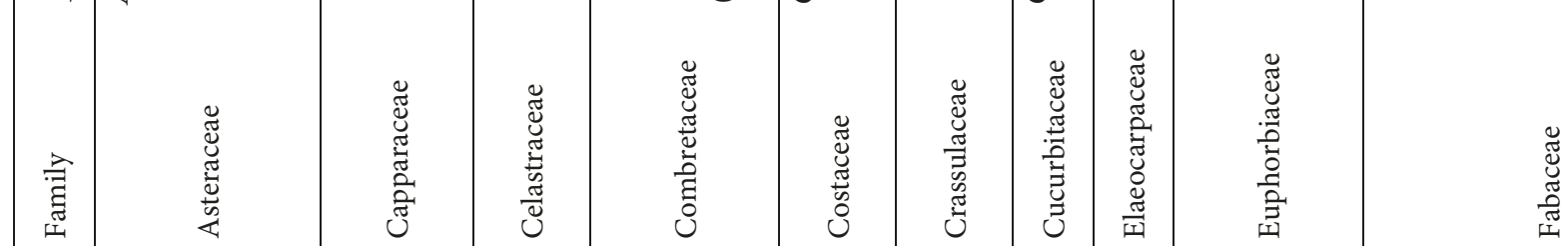




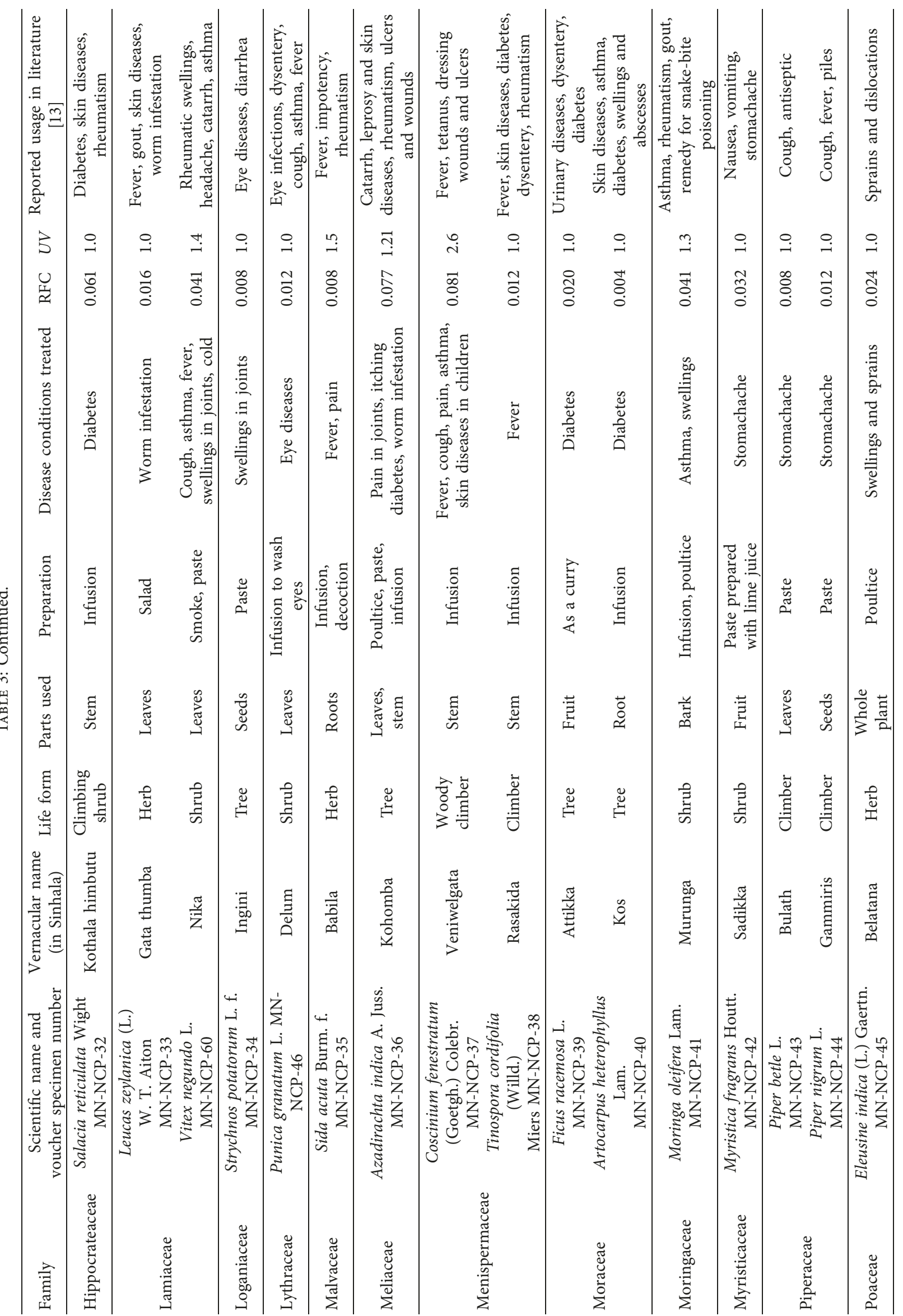




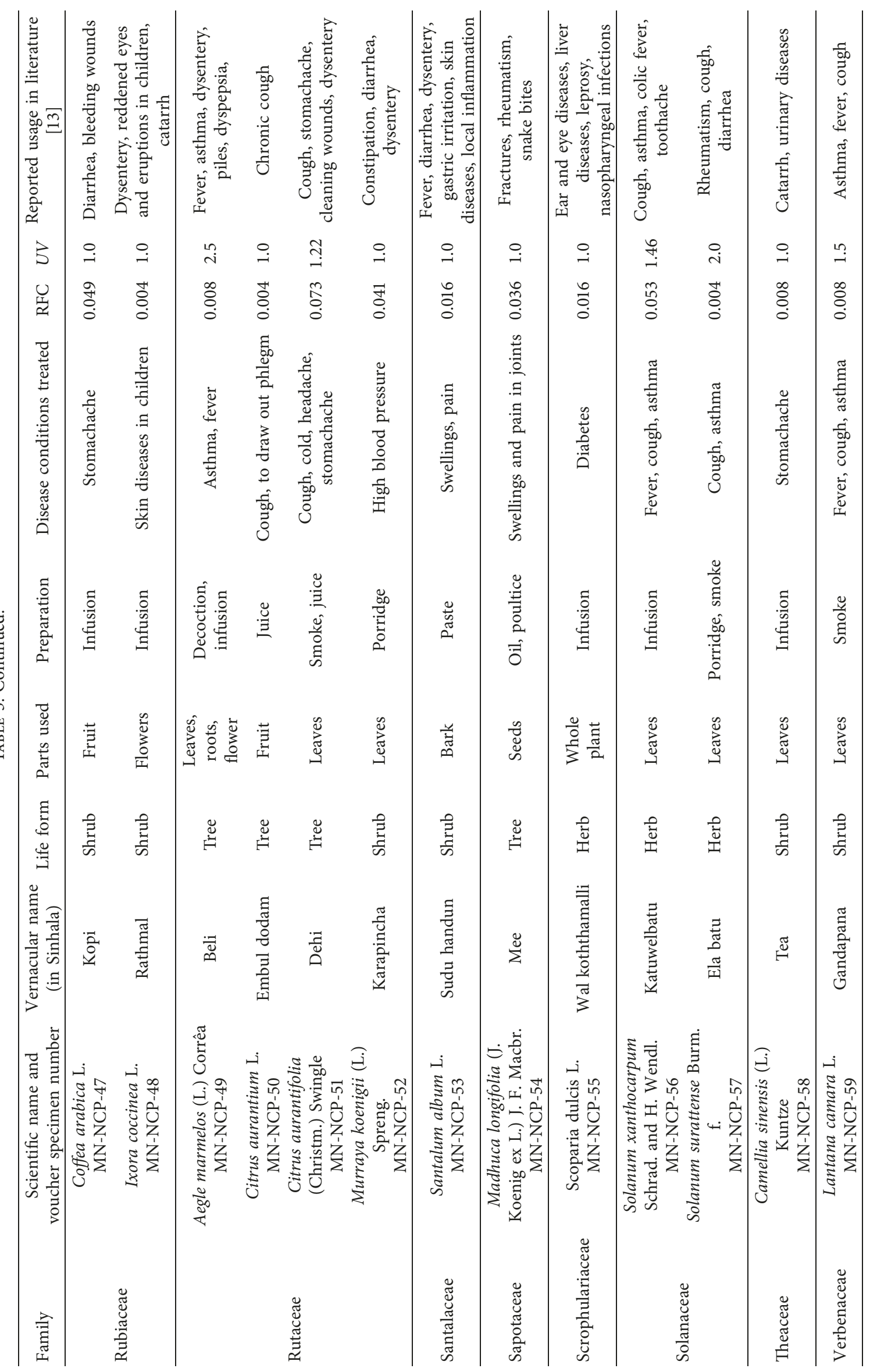




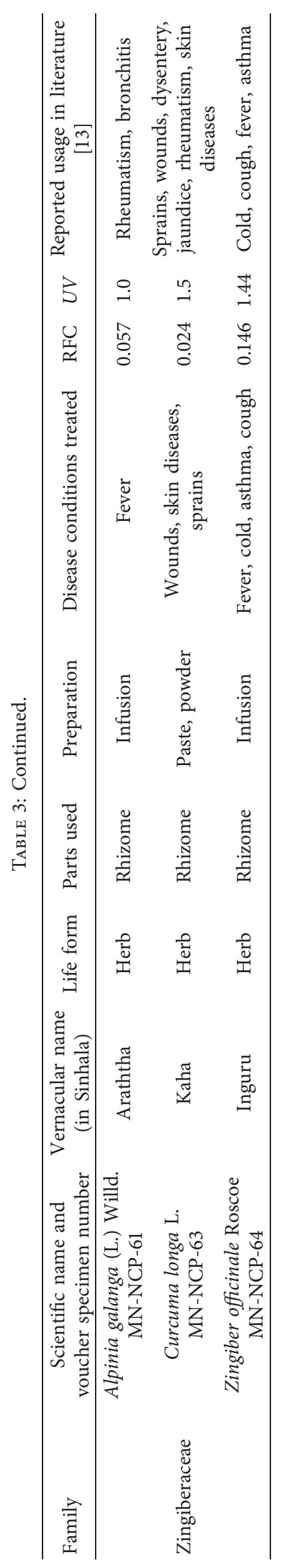




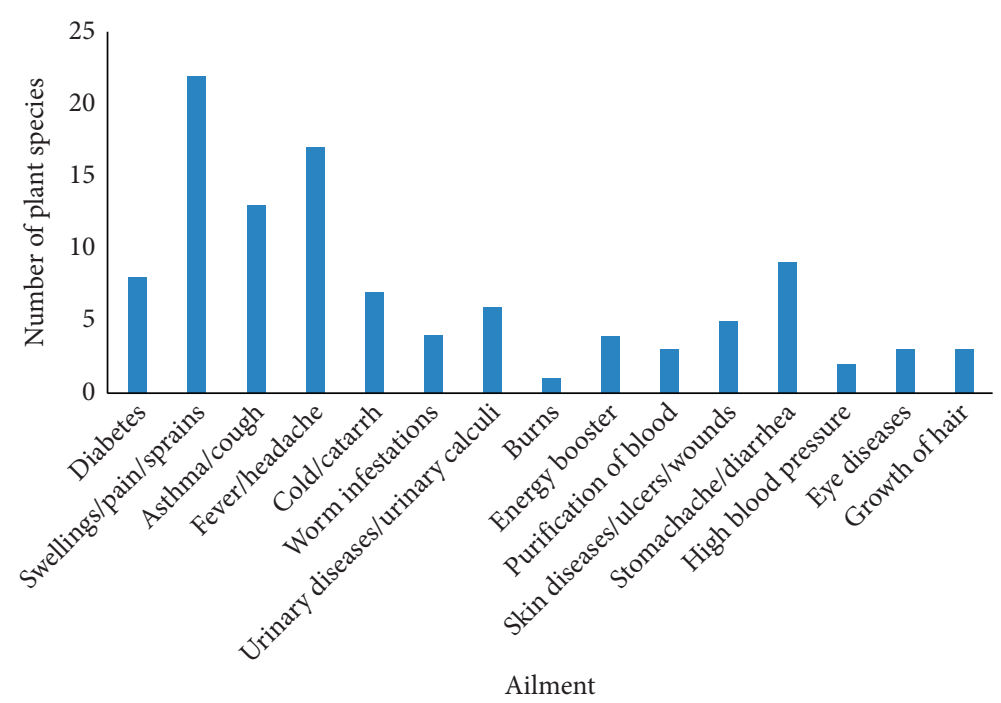

FIGURE 5: Number of plants used against different disease conditions.

an endemic species [8]. S. reticulata Wight is widely popular among Sri Lankans as an effective remedy for diabetes; thus, there is an increased demand for commercial products prepared from stems of this plant, which could make it highly vulnerable for extinction. Hence, appropriate conservation measures are urgently required to cultivate such valuable medicinal plants and thereby to reduce the pressure on overexploitation from natural habitats. On the other hand, plant species like Zingiber officinale Roscoe and Coriandrum sativum L. are not threatened by overharvesting despite the high demand, particularly due to the cultivation of $Z$. officinale Roscoe in most of the home gardens throughout the country not only for medicinal but also for culinary purposes as well as the availability of $C$. sativum L. as an imported spice in the local markets in Sri Lanka.

Although the majority of the people in the nonuser category (50.9\%) had used some kind of herbal therapeutics at some stage of their lives, the usage was discontinued mainly due to the difficulty in the preparation and collection of plant materials from their surroundings (59\%). In addition, the relatively long period of time taken for healing, unpleasant smell, and the taste has also hindered their use. Moreover, some have profusely refused such remedies, due to the unavailability of scientific records on the safety and the efficacy of herbal formulations. Interestingly, $75.4 \%$ of these nonusers mentioned that they would shift to herbal products if the efficacy of these products could be scientifically validated.

\section{Conclusion}

This study reports the first in-depth ethnobotanical survey in the North Central Province of Sri Lanka, where agriculture is the primary livelihood of the inhabitants of the area. Among 64 medicinal plants belonging to 42 reported plant families, the family importance value was highest in Zingiberaceae. The most popular medicinal plants among the inhabitants of Polonnaruwa district include Coriandrum sativum L.,
Zingiber officinale Roscoe, and Hygrophila auriculata (Schumach.) Heine. Despite the eroding folkloric knowledge that depended on the oral tradition for its transmission to successive generations, the indigenous herbal remedies are still popular among the local communities in the study area. Moreover, even the majority of the nonusers are ready to shift to herbal products upon the scientific validation of the therapeutic efficiency, and it signifies the necessity of comprehensive pharmacological and phytochemical investigations of these traditional formulations.

\section{Abbreviations \\ RFC: Relative frequency of citation \\ FIV: Family importance value \\ UV: Use value.}

\section{Data Availability}

The data used to support the findings of this study are included within the article.

\section{Ethical Approval}

The ethical approval was obtained from the ethical review committee, Faculty of Medicine, University of Ruhuna, Sri Lanka.

\section{Consent}

Informed consent was obtained in writing prior to the study.

\section{Conflicts of Interest}

The authors declare that there are no conflicts of interest regarding the publication of this article. 


\section{Acknowledgments}

The authors gratefully acknowledge "Faculty of MedicineResearch Grant 2015" from University of Ruhuna, Sri Lanka.

\section{Supplementary Materials}

Supplementary 1: the map of Polonnaruwa district (the district boundary is marked in purple, and the sites where the data were collected are marked with squares). Supplementary 2: the questionnaire which was used to collect the information on utility of herbal preparations and some demographic information of the informants. (Supplementary Materials)

\section{References}

[1] L. Zhang, H. Zhuang, Y. Zhang et al., "Plants for health: an ethnobotanical 25-year repeat survey of traditional medicine sold in a major marketplace in North-West Yunnan, China," Journal of Ethnopharmacology, vol. 224, pp. 119-125, 2018.

[2] M. F. Mahomoodally, "Traditional medicines in Africa: an appraisal of ten potent African medicinal plants," EvidenceBased Complementary and Alternative Medicine, vol. 2013, Article ID 617459, 14 pages, 2013.

[3] M. M. Pandey, S. Rastogi, and A. K. S. Rawat, "Indian traditional ayurvedic system of medicine and nutritional supplementation," Evidence-Based Complementary and Alternative Medicine, vol. 2013, Article ID 376327, 12 pages, 2013.

[4] P. B. Weragoda, "The traditional system of medicine in Sri Lanka," Journal of Ethnopharmacology, vol. 2, no. 1, pp. 71-73, 1980.

[5] D. S. A. Wijesundera, "Inventory, documentation and medicinal plant research in Sri Lanka," Medicinal Plant Research in Asia, vol. 1, pp. 184-195, 2004.

[6] A. K. Unial, C. Singh, B. Singh, M. Kumar, and J. A. T. da Silva, "Ethnomedicinal use of wild plants in Bundelkhand Region, Uttar Pradesh, India," Journal of Medicinal and Aromatic Plant Science and Biotechnology, vol. 5, pp. 81-86, 2011.

[7] T. van Andel and N. Barth, "Paul Hermann's ceylon herbarium (1672-1679) at Leiden, the Netherlands," Taxon, vol. 67, no. 5, pp. 977-988, 2011.

[8] T. van Andel, A. Scholman, and M. Beumer, "Icones plantarum malabaricarum: early 18th century botanical drawings of medicinal plants from colonial Ceylon," Journal of Ethnopharmacology, vol. 222, pp. 11-20, 2018.

[9] R. M. Dharmadasa, G. C. Akalanka, P. R. M. Muthukumarana, and R. G. S. Wijesekara, "Ethnopharmacological survey on medicinal plants used in snakebite treatments in Western and Sabaragamuwa provinces in Sri Lanka," Journal of Ethnopharmacology, vol. 179, pp. 110-127, 2016.

[10] M. T. Napagoda, T. Sundarapperuma, D. Fonseka, S. Amarasiri, and P. Gunaratna, "An ethnobotanical study of the medicinal plants used as anti-inflammatory remedies in Gampaha District-Western Province, Sri Lanka," Scientifica, vol. 2018, Article ID 9395052, 8 pages, 2018.

[11] D. M. A. Jayaweera, Medicinal Plants (Indigenous and Exotic) used in Ceylon, Part 1-5, National Science Council, Colombo, Sri Lanka, 1982.

[12] N. D. Namsa, H. Tag, M. Mandal, P. Kalita, and A. K. Das, “An ethnobotanical study of traditional anti-inflammatory plants used by the Lohit community of Arunachal Pradesh, India," Journal of Ethnopharmacology, vol. 125, no. 2, pp. 234-245, 2009.

[13] M. Umair, M. Altaf, and A. M. Abbasi, “An ethnobotanical survey of indigenous medicinal plants in Hafizabad district, Punjab-Pakistan," PLoS One, vol. 12, no. 6, Article ID e0177912, 2017.

[14] A. M. Towns, S. Ruysschaert, E. van Vliet, and T. van Andel, "Evidence in support of the role of disturbance vegetation for women's health and childcare in Western Africa," Journal of Ethnobiology and Ethnomedicine, vol. 10, no. 1, p. 42, 2014.

[15] S. Kayani, M. Ahmad, M. Zafar et al., "Ethnobotanical uses of medicinal plants for respiratory disorders among the inhabitants of Gallies-Abbottabad, Northern Pakistan," Journal of Ethnopharmacology, vol. 156, pp. 47-60, 2014.

[16] D. Diallo, B. Hveem, M. A. Mahmoud, G. Berge, B. S. Paulsen, and A. Maiga, "An ethnobotanical survey of herbal drugs of Gourma district, Mali," Pharmaceutical Biology, vol. 37, no. 1, pp. 80-91, 1999.

[17] Department of Census and Statistics, District Statistical Hand Book Polonnaruwa, Department of Census and Statistics, Battaramulla, Sri Lanka, 2016.

[18] M. D. Dassanayake and F. R. Fosberg, A Revised Handbook to the flora of Ceylon, Vol. 1-14, Amerind Publishers, New Delhi, India, 1980-2000.

[19] K. Šavikin, G. Zdunić, N. Menković et al., "Ethnobotanical study on traditional use of medicinal plants in South-Western Serbia, Zlatibor district," Journal of Ethnopharmacology, vol. 146, no. 3, pp. 803-810, 2013.

[20] S. Vitalini, M. Iriti, C. Puricelli, D. Ciuchi, A. Segale, and G. Fico, "Traditional knowledge on medicinal and food plants used in Val San Giacomo (Sondrio, Italy)-an alpine ethnobotanical study," Journal of Ethnopharmacology, vol. 145, no. 2, pp. 517-529, 2013.

[21] L. Ferrero-Miliani, O. H. Nielsen, P. S. Andersen, and S. E. Girardin, "Chronic inflammation: importance of NOD2 and NALP3 in interleukin-1beta generation," Clinical and Experimental Immunology, vol. 147, no. 2, pp. 227-235, 2007.

[22] F. T. Ishmael, "The inflammatory response in the pathogenesis of asthma," Journal of the American Osteopathic Association, vol. 111, no. 11, pp. S11-S17, 2011. 


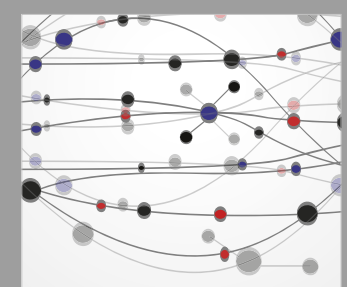

The Scientific World Journal
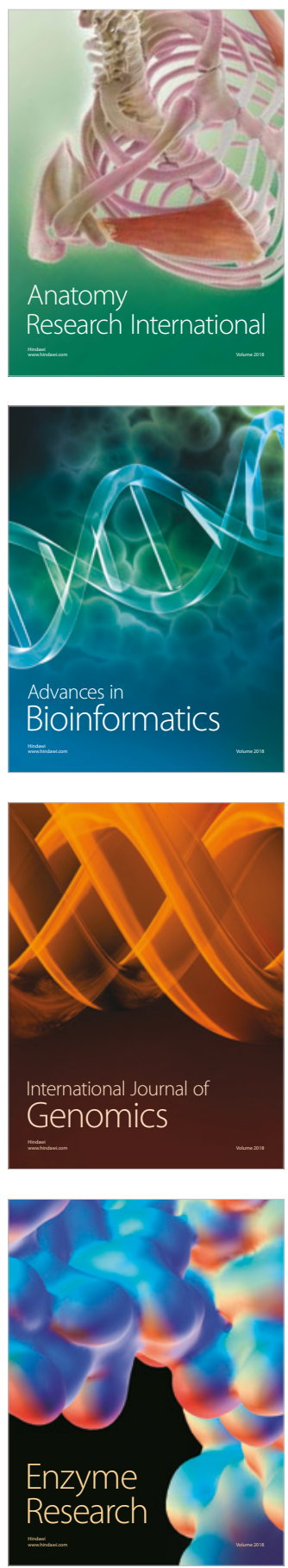
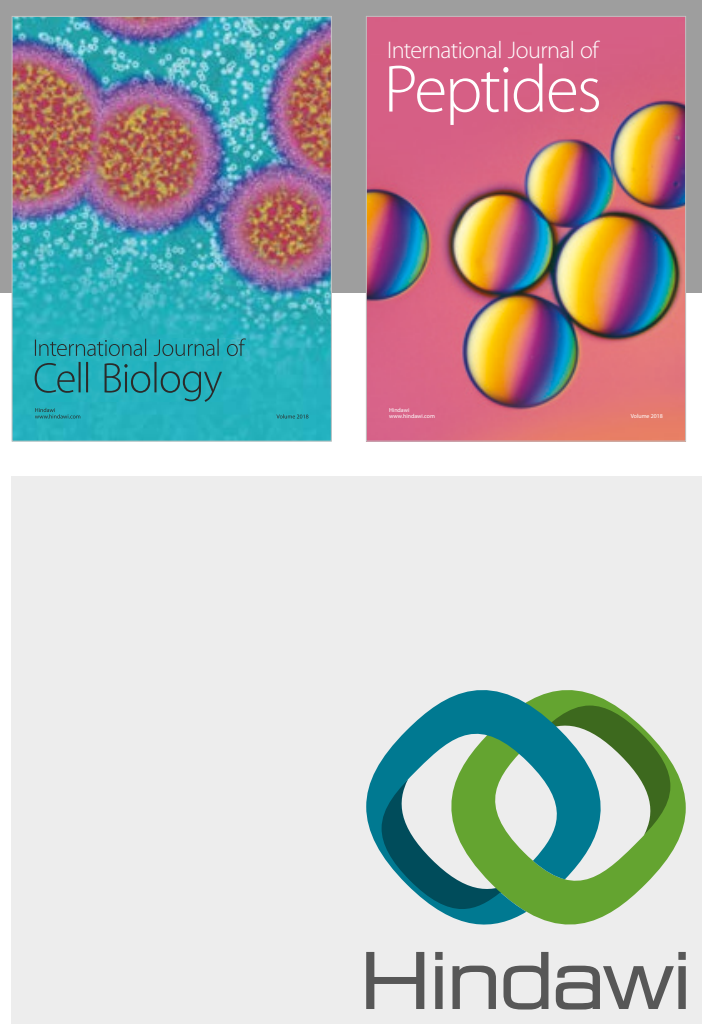

Submit your manuscripts at

www.hindawi.com
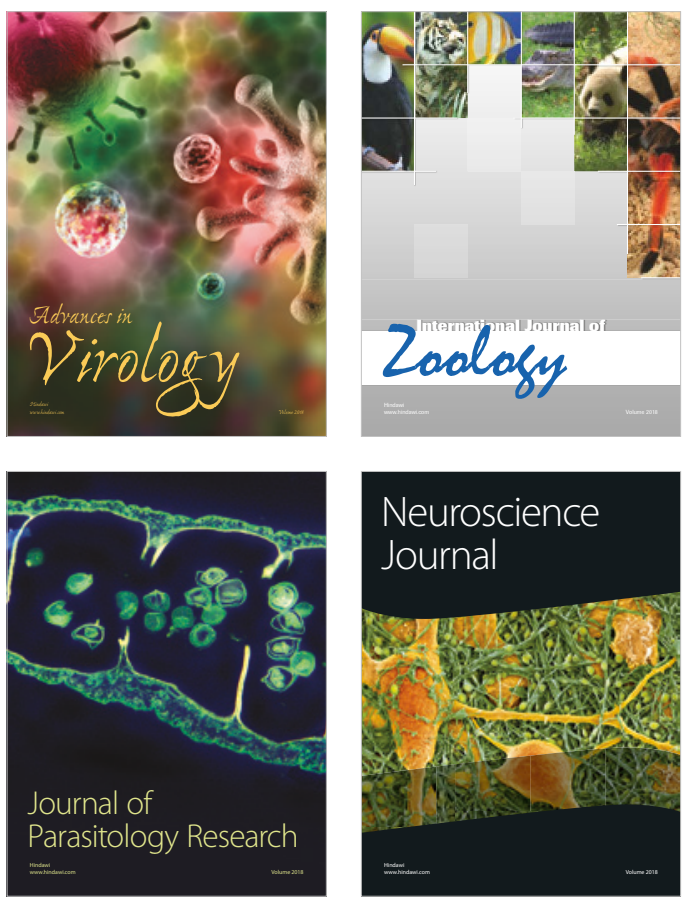
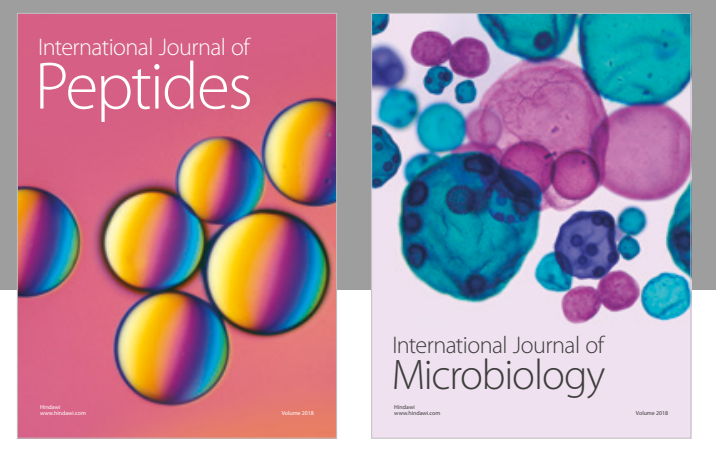

nternational Journal of Microbiology
Journal of
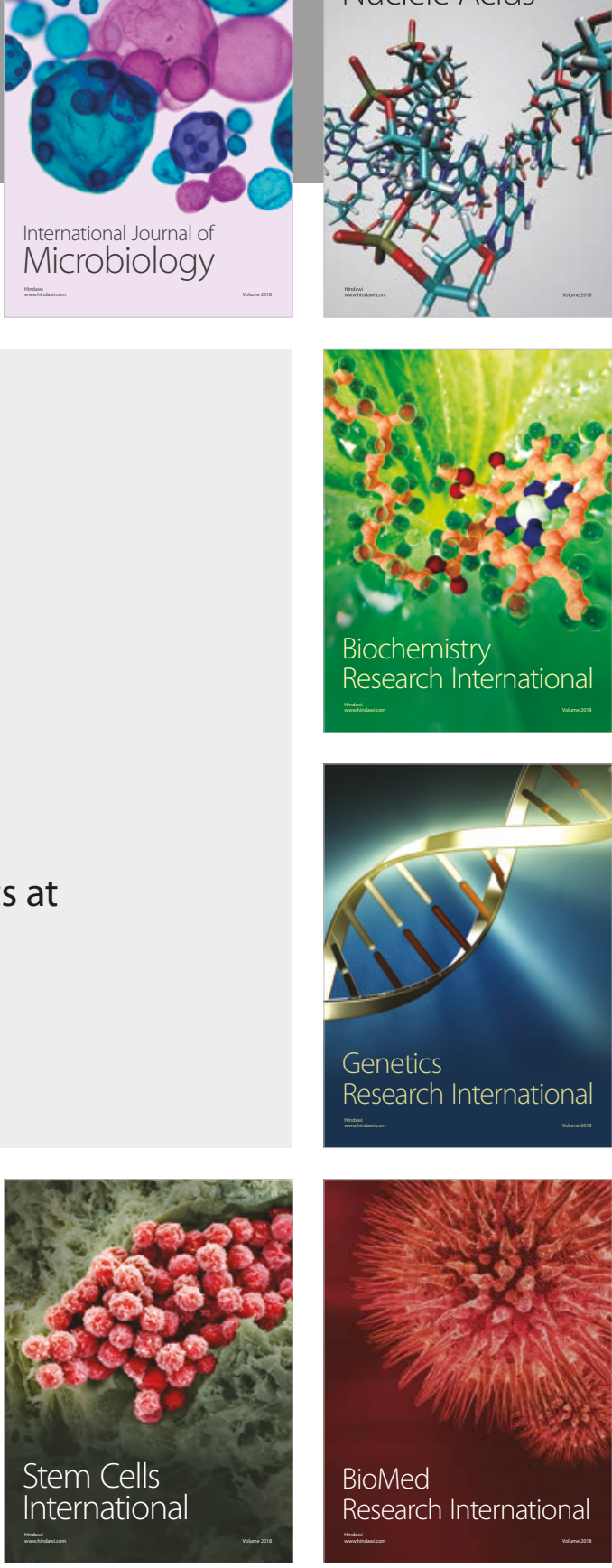
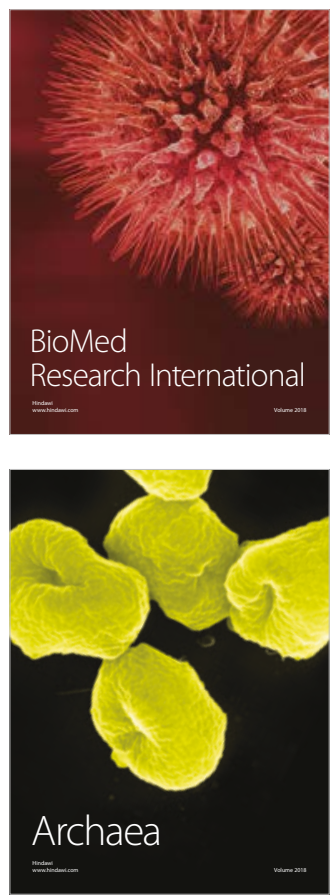